\title{
Troisième voyage du Sieur Paul Lucas dans le Levant, mai 1714-novembre 1717, présenté par Henri Duranton
}

\section{Paola Sosso}

\section{(2) OpenEdition}

\section{Journals}

\section{Edizione digitale}

URL: http://journals.openedition.org/studifrancesi/34747

DOI: $10.4000 /$ studifrancesi.34747

ISSN: 2421-5856

\section{Editore}

Rosenberg \& Sellier

\section{Edizione cartacea}

Data di pubblicazione: 1 novembre 2005

Paginazione: 422

ISSN: 0039-2944

\section{Notizia bibliografica digitale}

Paola Sosso, «Troisième voyage du Sieur Paul Lucas dans le Levant, mai 1714-novembre 1717, présenté par Henri Duranton», Studi Francesi [Online], 146 (XLIX | II) | 2005, online dal 30 novembre 2015, consultato il 18 avril 2021. URL: http://journals.openedition.org/studifrancesi/34747 ; DOI: https:// doi.org/10.4000/studifrancesi.34747

Questo documento è stato generato automaticamente il 18 avril 2021.

\section{cc) $($ ) $\ominus$}

Studi Francesi è distribuita con Licenza Creative Commons Attribuzione - Non commerciale - Non opere derivate 4.0 Internazionale. 


\title{
Troisième voyage du Sieur Paul Lucas dans le Levant, mai 1714-novembre 1717, présenté par Henri Duranton
}

\author{
Paola Sosso
}

\section{NOTIZIA}

Troisième voyage du Sieur Paul Lucas dans le Levant, mai 1714-novembre 1717, présenté par Henri DURANTON, Saint-Etienne, Publications de l'Université de Saint-Etienne, 2004, pp. 334.

1 Come negli altri resoconti (pubblicati in precedenza allinterno di questa stessa collezione), anche in questo caso Paul Lucas non fornisce dati precisi riguardo alla scelta delle mete da visitare, né riguardo ai dati cronologici. Partito da Parigi nel 1714, tornato nel 1717, il viaggiatore rivisita luoghi già descritti in parte nelle opere precedenti, ma il punto di vista è cambiato (si legga a tal proposito la parte iniziale del libro IV), anche grazie alla collaborazione dell'abbé Banier, membro dell'Académie des Inscriptions et Belles Lettres, che ha dato forma compiuta agli appunti di Lucas. Il carnet de route si arricchisce così di riferimenti ai classici latini e greci, mentre la sintesi tra récit au quotidien e savantes conjectures crea quasi sempre un tono originale in cui domina la curiosità del viaggiatore, alieno dai pregiudizi del suo tempo, come testimonia quanto leggiamo nel libro V: «[...] un voyageur ne doit-il pas rendre compte des traditions de chaque pays, quelque ridicules qu'elles soient? Les savants y découvriront peut-être les fondements de quelque vérité intéressante». Un rapido riassunto del contenuto dei sei libri favorisce la comprensione del lungo itinerario percorso, da Marsiglia alla Turchia, da Cipro all'Egitto, fino all'ultimo capitolo, dedicato a una descrizione generale della terra dei faraoni, in cui non è facile distinguere gli elementi nati dalla penna di Lucas da quelli inseriti a tavolino dall'erudito, soprattutto laddove compare un serrato confronto tra civiltà antica e moderna e un'appassionata ricerca di elementi comuni tra il mondo di ieri e quello di oggi (si vedano in particolare 
le pp. 296 e le seguenti). Chiude il volume l'indice dei nomi di luogo, quello dei nomi di persona e un'utile lista di Mots rares. 